\title{
The Organization for Economic Cooperation and Development: Challenges for Risk Assessment
}

\author{
Sally L. McCAMMON*
}

Biotechnology Regulatory Services, Animal and Plant Health Inspection Service, United States Department of Agriculture, 4700 River Rd, Riverdale MD 20737, Maryland, USA

The Organization for Economic Cooperation and Development's (OECD) Working Group for the Harmonization of Regulatory Oversight (Working Group) has taken the opportunity over the last several years to identify the challenges to environmental risk assessment of transgenic organisms, particularly plants. These initiatives have included most importantly, a report to the G8, the Rapporteur's Report from the OECD international symposium on LMOs and the Environment; and an internal workshop on Review of Consensus Documents and Future Work in Harmonization that emphasized priority setting. The outcome of these endeavors has informed the development of subsequent programs of work adopted by the Working Group. This paper identifies points raised at these conferences and meetings that relate to the science underpinning risk/safety assessment. Many of the points are similar over the timeframe of these endeavors and are still of current importance. The discussions at the OECD workshop on risk assessment held in Korea during the 9th International Symposium on the Biosafety of Genetically Modified Organisms will also influence the subsequent projects and priorities of the Working Group.

\section{INTRODUCTION}

The Organization for Economic Cooperation and Development's (OECD) Working Group for the Harmonization of Regulatory Oversight (Working Group) is unique internationally. Working Group harmonization activities are to provide aid in environmental risk/safety assessment of transgenic organisms and are therefore primarily scientifically and technically focused. The work products are documents developed by the regulators and assessors responsible for evaluating these organisms. Work focuses on identification and articulation of key questions, as well as information and tools to be considered or used by regulators. These documents are developed from a regulator's perspective and for use by regulators and risk assessors as they evaluate the products of modern biotechnology.

As part of their ongoing work, the Working Group can develop public reports, sponsor international conferences and internal workshops and documents for the public the perspectives of the regulators that participate in the Working Group. The Wordking Group also engages with the scientific community on the current information regarding transgenic organisms and evaluates the ongoing work to assure that it is focused and relevant. The following

\footnotetext{
* Corresponding author:

Sally.L.McCammon@aphis.usda.gov
}

is a summary of important points that have been raised during discussions of the scientific challenges to environmental risk assessment in the Working Group's response to a request from the G8 (2000), at the OECD conference on LMOs and the Environment (2001), and the internal workshop on Review of Consensus Documents and Future Work in Harmonization (2003) that emphasized priority setting.

\section{G8 REPORT}

The G8 report (OECD, 2000) came out of a request from the G8 countries in June of 1999 that came specifically to the Working Group and the OECD Task Force for Novel Food and Feed (Task Force) to look at the implications of biotechnology and other aspects of food safety. While it is not unusual for the G8 to make requests of the OECD in general on specific topics of interest, what was highly unusual in this case was that the request was specifically addressed to two bodies within the OECD, the Working Group and the Task Force, two technical bodies that deal with, respectively, environmental and food safety assessment of transgenic organisms. Three reports by different bodies within the OECD and three international conferences sponsored by the OECD 
were the result of the request from the G8. The report from the Working Group, finalized within the allotted year, was to the OECD Council, a body formed of ambassadors from member countries to the OECD. The six months time frame for developing the response was extremely rapid for an international body and required extraordinary collaboration and commitment by the delegates to the Working Group to complete. The major thrust of the report was to provide recommendations encouraging continual review and approval of assessment methods and approaches.

The challenges for risk/safety assessment identified by the Working Group in its report to the G8 included those from capacity building, new scientific and technological developments and broader policy objectives. A major challenge in capacity building, particularly for developing countries, is the lack of national infrastructures to do adequate assessments. This is coupled with the need to adequately address the local geography, biota, climate and soil in environmental assessments. If a developing country is also the center of origin of a crop plant then the need to understand and address potential impacts on wild relatives and land races is compounded.

New scientific and technological developments arise as the range of types of transgenic organisms increase plants, micro-organisms, and animals (including insects). The establishment of familiarity may be more difficult for these organisms as the untransformed organism may not be as widely used and understood as the commodity crop plants that are now genetically engineered and commercialized. Methods to assess such organisms will need to be developed. This expanding number of engineered organisms is accompanied by an increasing number of traits; genes that are derived from new sources and used in new combinations; and the advent of stacked genes. For the evaluation of transgenic organisms, the identification and evaluation of short term effects is well defined while addressing long term effects may require the development of ecological models.

Many countries have broad policy objectives for agriculture and the environment and the assessment of transgenic organisms fits into this context; broad objectives such as minimizing adverse effects on the environment or assuring human health. As agriculture has detrimental effects on the environment, whether or not transgenic organisms are used, policy objectives may be to enhance beneficial environmental effects of agriculture; to promote sustainable development which links economic and environmental objectives; and to encourage life cycle assessments.

There is a need to streamline existing risk/safety assessments - the assessments of products very similar to each other that have been reviewed for a decade or more with little or no concern. The experience developed with existing products can be used to understand and evaluate new products. This will allow a focus of assessment resources on new types of products.

\section{CONFERENCE ON LMOS AND THE ENVIRONMENT}

To complement international OECD conferences on food safety and stakeholder input held in Scotland and Thailand, respectively, in response to the G8 request, the OECD initiated a conference on the environmental aspects of transgenic organisms or living modified organisms - LMOs. In November, 2001 the Working Group sponsored an international conference on LMOs and the Environment in Raleigh, North Carolina, hosted by the United States. The resultant proceedings (OECD, 2002) and Rapporteur's Report (OECD, 2001) can be found at the OECD BioTrack website.

Two primary objectives of the conference were the identification of the issues related to environmental assessment of transgenic crops as well as future work on the scientific aspects of environmental risk assessment. As has been acknowledged in the 9th International Symposium on Genetically Modified Organisms and other venues, many countries have assessment systems in place that are based upon very similar sets of requirements. In addition, there is a large body of knowledge that exists regarding the transgenic crops that have been commercialized. However, advances in science, particularly in genomics, proteomics, and metabolomics - systems biology - will impact the rapidity and types of new product development and this will require regulatory systems to adapt.

There were a number of outstanding issues that were identified at the conference that have still not been resolved including the identification of appropriate baseline information and the constitution of appropriate data sets for identifying hazards and determining the likelihood that a hazard will occur. Continued concern exists over the ability of scientists, risk assessors, and regulators to distinguish between what assessors "need to know" versus what is "nice to know". This last dilemma is an outgrowth of the ever increasing availability of information and the lack of agreed upon harms to the environment and end-points for determining the impact of any product or attribute of a product on these harms. In addition, the focus on transgenic crops over the past decade or so has led to a shifting perspective over the impacts of crops developed by more conventional and unregulated methods.

Even though there is a large body of information available on the transgenic crops commercialized so far, much of this is not in the published literature as it is difficult to publish results when there is a lack of significant 
impact (negative results) and this has dampened efforts to argue a convincing case regarding decisions over assessments accomplished by sophisticated national regulatory systems.

To advance risk assessment, further understanding is needed of gene flow, the development of resistance and the impact on non-target species, and the diversity of ecological systems through the development of baseline data, appropriate databases, and assessment methodologies. A greater understanding of the mechanics and potential consequence of gene flow related to crop plants would provide the baseline necessary to understand the potential impact of a new trait introduced into a crop plant via genetic engineering. It would be very useful to assure that research on non-target organisms is relevant to actual ecosystems. The role of modeling in dealing with lack of information should be explored. Such knowledge would allow an understanding of interaction of transgenic organisms with ecosystems.

Several opportunities for international cooperation on research and assessment methods of transgenic organisms were identified through the discussions at the conference. These included developing consensus on how to more specifically define the environment for risk/safety assessment especially in regards to assessment of nontarget effects; determining the applicability of current assessment techniques to stacked genes and products of "systems" biology; addressing appropriate baselines for assessment and determination of long term effects; coming to consensus on what constitutes an adverse effect as well as developing risk assessment criteria and endpoints; developing more predictive tools for assessing the environmental impact of transgenic organisms; preparing for assessment of second generation transgenic organisms in environments already containing transgenic organisms; and determining whether information from genome analysis can resolve concerns over unexpected secondary functions of inserted genes.

\section{WASHINGTON WORKSHOP: REVIEW OF CONSENSUS DOCUMENTS AND FUTURE WORK IN HARMONIZATION}

In October, 2003, Canada, Mexico and the United States hosted a workshop for members and observers of the Working Group in Washington, D.C. on the Review of Consensus Documents and Future Work in Harmonization (Washington Workshop). The workshop was a result of the recognition in the Working Group's 2003-2005 program of work of the need to evaluate the major work of the Working Group to date, the biology and trait consensus documents, while recognizing that the Working Group was beginning to invest more resources in projects that addressed other future needs in regulatory harmonization. As planning for the workshop proceeded, one of the major objectives of the workshop became the development of mechanisms to enhance priority setting that would include the identification of major priorities such as the needs and challenges facing assessors, and prioritizing these challenges. Several categories of topics for future work in harmonization came out of the workshop; definitions and concepts, information elements, evaluation of hazards, and risk assessment methodologies. Under definitions and concepts, it became clear that many terms and concepts are used but there is a need to clarify international understanding of these concepts as they may or may not relate to environmental risk assessment. Such definitions are needed for terms such as substantial equivalence, familiarity, and environmental harm and for concepts of regional strategies for centers of origin or regional agricultural systems.

There is a need for agreement on the information elements or on what basic information should be collected for risk assessments. Such a project is currently being worked on within the Working Group, called Environmental Considerations for Risk/Safety Assessment for the Release of Transgenic Plants. For the evaluation of hazards, clarity is needed on what are those factors that may constitute a hazard to the environment.

Harmonization of risk assessment methodologies such as protocols and processes for measuring impact would be useful for both risk assessors and applicants to regulatory bodies. Examples of these are testing protocols to gather information, including lab tests such as non-target organism toxicity testing and dormancy germination tests as well as field tests to evaluate fitness in the environment and non-target organism toxicity. The development and use of appropriate and agreed upon models would be beneficial. Methodologies to aid in the use of information in decision-making such as environmental risk/safety assessment methodologies and clarification of decision thresholds would also be useful.

The biology consensus documents are a major work product of the OECD Working Group because they address the important aspects of plant biology needed to understand how the non-transgenic comparator interacts with the surrounding environment in order to then be able to understand any potential significant changes in that behavior due to the addition of new genetic material in this biological context. Knowledge of the parental organism of the transgenic organism is important to determine the level of familiarity. The Working Group has developed about 20 plant biology consensus documents useful to applicants, regulators/risk assessors, and the public for risk assessment. Some countries allow the reference to or submission of an OECD plant biology consensus document in lieu of developing a section on plant biology as part 
of an application to regulatory authorities for review of a transgenic plant product.

The Working Group participants also include ad hoc observers from non-member countries, particularly those countries that are developing transgenic products. Attendees at the workshop from those countries, included Brazil, the Russian Federation, and others who provided valuable insights allowing the workshop to focus on potential products that could be useful not only to OECD member countries but globally. The participants identified the following potential future plant biology consensus documents as being important: fava beans, plantain, alfalfa, sweet potato, pome fruits, safflower, eucalyptus, turf and forage grasses, cassava, sorghum, cabbage, tobacco, grape and barley. The potential traits or issues associated with traits identified for future consideration by the Working Group included pharmaceutical compounds, gene silencing, modified chemical composition, stress tolerance, fungal disease resistance, and male sterility. Addressing issues associated with stacked genes also were raised. From these listings, cassava garnered the distinction of top priority for plants and stress tolerance was identified as the top priority for traits.

The Working Group is aware that there are many new products under development that risk assessors and regulators will have to evaluate and these products will have new issues associated with them. For crop plants such issues include those associated with biopharming (the use of transgenic plants to generate pharmaceutical compounds) and exposure of the environment to biopharmed products; drought tolerance and how tropical countries might develop an understanding of the baseline of information needed to evaluate such products; impact on the rhizophere; review of the impact of new traits; phytoremediation; impact of traits conferring increased fitness; gene stacking; neutraceuticals; and centers of origin and diversity. All of these emerging issues need to be defined and addressed appropriately.

Several projects were the immediate result of the Washington Workshop and have moved the Working Group into the next stage of providing harmonized technical products directly useful to risk assessors and regulators evaluating genetically engineered products (OECD, 2005). These include the development of the Points to Consider for the Development of Biology Consensus Documents (PTC), published in 2006 (OECD, 2006a). In preparation for the Washington Workshop, the approximately 20 biology consensus documents that had been developed by the time of the workshop were evaluated for general similarities and differences by representatives from Japan and the Netherlands and this evaluation became the basis of the project. The PTC document meets multiple objectives: it provides a guide to authors of future biology consensus documents for inclusion of the critical information regarding the biology of the untransformed parent plant and it provides regulators and risk assessors with a guide to the kind of information about the untransformed plant that they should be aware of in their evaluations of transgenic plant products. Information categories and elements are identified and the rationale for the importance of each of these elements is articulated.

The first project related to transgenic animals was also an outgrowth of the Washington Workshop. A consensus document on the biology of Atlantic salmon is currently under development that will provide the baseline information for evaluating any impacts from transgenic Atlantic salmon - an organism whose development is being watched closely by regulators. Since the Washington Workshop, two additional workshops have been held, one in Moscow (OECD, 2006b) and the other in Trondheim, to identify the major issues associated with Atlantic salmon. The Working Group used the approach developed in the PTC document of identifying information categories and elements and their importance in relation to risk/safety assessment to draft an outline for this project.

The Working Group has been able to capitalize on its experience with the development of an approach to risk assessment of transgenic plants to agree upon and work through this crucial first step in providing the baseline information from which to evaluate any increased impacts of a transgenic salmon in the future.

Criteria useful for the prioritization of work products were also identified at the Washington Workshop. These are important given the myriad potential projects that might be undertaken as indicated in the preceding text. Before being undertaken by the Working Group, new projects should be able to promote harmonization, rely upon existing significant experience of member countries in whatever topic is undertaken, promote the capacity of member and non-member countries to do actual assessments; be accomplished in a reasonable timeframe; and address regulatory needs for conducting environmental risk assessment. In addition, resources in both member countries and the Secretariat should be available to accomplish the project. Any new project should provide a unique contribution from the OECD that cannot or has not been accomplished by the international community. It should build upon and complement the current body of work of the OECD and other international organizations.

\section{CONCLUSION}

The OECD Working Group is unique. It has provided a focal point internationally for consolidating global thinking on the scientific and technical issues that need to be addressed in environmental risk assessment and has 
provided venues for discussion of those issues. The organizing principle is risk assessment of transgenic organisms in the environment - the environment into which the organism is introduced and the interaction of the environment with the organism and the trait. The scope of the environment is broad, including both agricultural and natural aspects, and depends upon the region into which the organism is introduced. How the environment is defined is critical for any risk/safety assessment.

The three major undertakings sponsored by the OECD Working Group described in this paper to scan, synthesize, and pinpoint the issues of scientific importance to regulators each identified many issues in common over the years they were undertaken that are still of current interest. Such issues include the definition of what is meant by the environment which is critical when an assessment is undertaken, along with a need for harmonization of the understanding of what constitutes environmental harm as well as common understandings of the criteria for addressing such harms and agreeing on baseline data and on endpoints for the development of data to address those harms. The need for understanding whether modeling can address the concerns over predictability of risk assessments and the lack of certainty, continues to be raised. Also, the application of systems biology to assessment and understanding the consequences of gene flow and its relationship to traits that may move from transgenic organisms to other organisms in the environment. Many other issues are continuing threads in the discussion of the assessment of transgenic organisms. The scientific and regulatory communities continue to work on these issues. The Working Group continues to provide the venue to develop international guidance and support on the issues through the development of technical documents that support risk/safety assessment.

\section{DISCLAIMER}

Sally L. McCammon, Ph.D. is the Science Advisor at BRS, APHIS, USDA. The views expressed in this paper are those of the author and do not necessarily represent those of the United States Government.

\section{REFERENCES}

Organization for Economic Cooperation and Development (2000) Report of the Working Group on Harmonization of Regulatory Oversight in Biotechnology. www.oecd.org/department/0,2688,en_2649_34385_1_ 1_1_1_1,00.html 65 p

Organization for Economic Cooperation and Development (2001) LMOS and the Environment: An International Conference - Final Rapporteur's Report. www.oecd.org/department/0,2688,en_2649_34385_1_1_ 1_1_1,00.html $11 \mathrm{p}$

Organization for Economic Cooperation and Development (2002) LMOS and the Environment: Proceedings of an International Conference. C. Roseland, ed. www.oecd.org/department/0,2688,en_2649_34385_1_ 1_1_1_1,00.html 392 p

Organization for Economic Cooperation and Development (2005) An Introduction to the Biosafety Consensus Documents of OECD's Working Group for Harmonisation in Biotechnology. www.oecd.org/department/0,2688,en_2649_34385_1_

1_1_1_1,00.html 19 p

Organization for Economic Cooperation and Development (2006a) Points to consider for Consensus Documents on the Biology of Cultivated Plants. www.oecd.org/department/ 0,2688,en_2649_34385_1_1_1_1_1,00.html 24 p

Organization for Economic Cooperation and Development (2006b) Abstracts of the OECD Workshop on the Biology of Atlantic Salmon (Salmo salar). www.oecd.org/department/0,2688,en_2649_34385_1_ 1_1_1_1,00.html $30 \mathrm{p}$ 